\title{
Análise econômica da adubação nitrogenada em feijoeiro de inverno sob plantio direto ${ }^{1}$
}

\author{
Michelle Traete Sabundjian², Orivaldo Arf ${ }^{2}$, \\ Maria Aparecida Anselmo Tarsitano², Flávio Hiroshi Kaneko², Daiene Camila Dias Chaves Corsini²
}

\begin{abstract}
Economic analysis of nitrogen

fertilization in winter bean plant under no-tillage system

With the expansion and diversity of the no-tillage system, it is necessary to evaluate the economic benefits generated throughout the production cycle, especially those related to remnants of previous crops and nitrogen fertilizer management of succeeding crops. This study aimed to evaluate the economic viability of four cover nitrogen doses on winter bean grain yield grown under no-tillage system after different crops. The experimental design was randomized blocks with four replications, in a $8 \times 4$ factorial scheme, with 32 treatments consisting of a combination of crop remnants (mayze; mayze - Azospirillum brasilense; Urochloa ruziziensis; Urochloa ruziziensis - Azospirillum brasilense; mayze + U. ruziziensis; mayze - A. brasilense $+U$. ruziziensis; mayze $+U$. ruziziensis A. brasilense; mayze - A. brasilense $+U$. ruziziensis - A. brasilense) and cover nitrogen doses $\left(0 \mathrm{~kg} \mathrm{ha}^{-1}, 30 \mathrm{~kg} \mathrm{ha}^{-1}, 60 \mathrm{~kg} \mathrm{ha}^{-1}\right.$ and $\left.90 \mathrm{~kg} \mathrm{ha}^{-1}\right)$. It was possible to conclude that the highest grain yield of winter bean plants irrigated by aspersion was obtained with the use of $90 \mathrm{~kg} \mathrm{ha}^{-1}$ of cover nitrogen in succession to Urochloa ruziziensis without the inoculation of Azospirillum brasilense. In order to improve profits, it is recommended to apply $90 \mathrm{~kg} \mathrm{ha}^{-1}$ of cover nitrogen to bean crops succeeding the other crops, except for inoculated Urochloa ruziziensis.
\end{abstract}

KEY-WORDS: Phaseolus vulgaris L.; Azospirillum brasilense; Brazilian Savannah.

\section{INTRODUÇÃO}

O feijoeiro é uma leguminosa de grande importância econômica, social e alimentar, no Brasil. De cada dez brasileiros, sete consomem feijão diariamente e o grão, além de ser típico da culinária do País, é fonte de proteína vegetal, vitaminas do complexo B, sais minerais, ferro, cálcio e fósforo (Brasil 2013).

Para a safra brasileira de feijão, estima-se que a área total, em 2014/2015, possa atingir 3,23 milhões

\section{RESUMO}

Com a expansão e diversidade do sistema plantio direto, deve-se avaliar os benefícios econômicos gerados ao longo dos ciclos produtivos, com destaque para aqueles relacionados aos restos culturais da cultura antecessora e ao manejo da adubação nitrogenada da cultura sucessora. Este trabalho objetivou avaliar a viabilidade econômica de quatro doses de nitrogênio em cobertura, na produtividade de grãos de feijoeiro de inverno cultivado no sistema plantio direto, após diferentes culturas. $\mathrm{O}$ delineamento experimental utilizado foi o de blocos ao acaso, com quatro repetições, em esquema fatorial $8 \times 4$, com 32 tratamentos constituídos pela combinação de restos culturais (milho; milho - Azospirillum brasilense; Urochloa ruziziensis; Urochloa ruziziensis - Azospirillum brasilense; milho + U. ruziziensis; milho - A. brasilense $+U$. ruziziensis; milho $+U$. ruziziensis - A. brasilense; milho - A. brasilense + $U$. ruziziensis - $A$. brasilense) e doses de nitrogênio em cobertura $\left(0 \mathrm{~kg} \mathrm{ha}^{-1}, 30 \mathrm{~kg} \mathrm{ha}^{-1}, 60 \mathrm{~kg} \mathrm{ha}^{-1}\right.$ e $\left.90 \mathrm{~kg} \mathrm{ha}^{-1}\right)$. Concluiu-se que o maior acréscimo de produtividade de grãos do feijoeiro de inverno irrigado por aspersão foi obtido com a utilização de $90 \mathrm{~kg} \mathrm{ha}^{-1}$ de nitrogênio em cobertura, em sucessão a Urochloa ruziziensis, sem a inoculação de Azospirillum brasilense. Recomenda-se, para obtenção da maior margem de ganho, a aplicação de $90 \mathrm{~kg} \mathrm{ha}^{-1}$ de nitrogênio em cobertura, na cultura do feijoeiro em sucessão às outras culturas, exceto para Urochloa ruziziensis inoculada.

PALAVRAS-CHAVE: Phaseolus vulgaris L.; Azospirillum brasilense; Cerrado.

de hectares, o que representa uma diminuição de $3 \%$, em relação à safra passada, e a produção nacional deverá situar-se entre 3,15 e 3,20 milhões de toneladas, representando decréscimo de $8 \%$, quando comparada à última safra (Conab 2014).

Dentre as práticas conservacionistas de produção do feijoeiro de inverno, o sistema plantio direto torna-se interessante, pois, de acordo com Gassen \& Gassen (1996), a manutenção de restos vegetais na superfície do solo é uma das vantagens do sistema

1. Trabalho recebido em set./2013 e aceito para publicação em set./2014 (nº registro: PAT 26591).

2. Universidade Estadual Paulista Júlio de Mesquita Filho (Unesp), Faculdade de Engenharia, Ilha Solteira, SP, Brasil. E-mails: michelletraete@hotmail.com, arf@agr.feis.unesp.br, maat@agr.feis.unesp.br, fhkaneko@hotmail.com, daiene6@hotmail.com. 
que, além de proteger o mesmo da radiação solar, dissipa a energia de impacto das gotas de chuva, reduz a evaporação de água, aumenta a eficiência da ciclagem dos nutrientes e assegura a manutenção da matéria orgânica do solo, em comparação com o preparo convencional (Alcântara et al. 2000, Boer et al. 2007).

Para viabilizar o plantio direto, é necessária a utilização de plantas de cobertura que possibilitem, além da produção e manutenção de elevada quantidade de palhada sobre o solo, acréscimos de produtividade para as culturas em sucessão (Fiorentin et al. 2012). Para isso, uma das opções seria o consórcio de culturas produtoras de grãos (milho, por exemplo) e gramíneas perenes com elevado potencial para formação de palhada e de ciclagem dos nutrientes presentes nas camadas mais profundas do solo (Silva \& Mielniczuk 1997).

Aproveitar de forma racional os sistemas produtivos criados a partir do plantio direto requer conhecimento de diversas áreas de estudo. Dentre elas, destaca-se a administração financeira da propriedade, que é importante para avaliar a rentabilidade das práticas adotadas dentro dos sistemas de produção, auxiliando na tomada de decisão nos investimentos.

O nitrogênio é um dos nutrientes mais absorvidos e importantes para o feijoeiro e, quando aplicado na dose recomendada, promove rápido crescimento e aumento da folhagem e do teor de proteína nas sementes, bem como favorece os micro-organismos do solo que decompõem a matéria orgânica, além de incrementar o teor de matéria seca, sendo importante durante todo o ciclo, especialmente nas fases de floração e enchimento de grãos (Malavolta 1979). Por outro lado, é o nutriente aplicado em maior quantidade à cultura do feijão, o mais limitante ao crescimento e desenvolvimento da planta e o que mais onera o seu custo de produção (Amado et al. 2002).

De acordo com Barbosa Filho \& Silva (2000) e Barbosa Filho et al. (2004, 2005), a ureia aplicada superficialmente, e com uso de irrigação, é a opção com maior retorno econômico para a adubação nitrogenada em cobertura. Há necessidade, portanto, de ajuste, levando-se em consideração as culturas antecessoras e a dose para obtenção da maior margem de lucro, já que, muitas vezes, o insucesso no cultivo do feijoeiro é determinado pela adubação nitrogenada inadequada.

Ao realizarem a análise comparativa de custos de produção de feijão, com a utilização de ureia e nitrato de amônio, Rapassi et al. (2003) observaram que o nitrogênio promoveu incremento na produção com as duas fontes de $\mathrm{N}$ utilizadas, porém, as diferenças não foram significativas, justificando, assim, a importância da análise econômica, a qual também evidenciou que a ureia foi a fonte mais compensatória.

Segundo Barbosa Filho et al. (2004), do ponto de vista econômico, a dose de $\mathrm{N}$ que corresponde ao maior rendimento de grãos pode não corresponder à dose mais rentável e, portanto, não ser a mais adequada para recomendação ao produtor.

As informações econômicas de uma cultura são de fundamental importância para o agricultor, pois auxiliam na combinação dos recursos utilizados em sua produção, visando à obtenção de melhores resultados (Crepaldi 1998).

Uma das técnicas capazes de possibilitar a economia de fertilizantes nitrogenados é a fixação biológica do nitrogênio, que poderá ser realizada pelo processo associativo de gramíneas com bactérias diazotróficas do gênero Azospirillum (Hungria 2011). Desse modo, além da economia para os agricultores, o uso dessa tecnologia em gramíneas, durante o verão, contribui para o ambiente e poderá incrementar a qualidade química da palhada que antecederá o feijoeiro cultivado no inverno.

Dessa forma, pesquisas que possam contribuir para uma indicação eficiente, do ponto de vista não só agronômico, mas também econômico do sistema plantio direto, em relação à escolha da cultura antecessora e à quantidade de nitrogênio utilizado em cobertura, são de extrema importância para os produtores de feijão.

Diante desses fatos, este trabalho objetivou avaliar economicamente a aplicação de nitrogênio em cobertura na produtividade de grãos de feijoeiro de inverno cultivado no sistema plantio direto.

\section{MATERIAL E MÉTODOS}

O estudo foi desenvolvido na Fazenda de Ensino, Pesquisa e Extensão da Universidade Estadual Paulista "Júlio de Mesquita Filho", localizada em Selvíria (MS) (20²2'S, 51²2'W e altitude de $335 \mathrm{~m})$. O solo do local é um Latossolo Vermelho, epi-eutrófico álico, textura argilosa (Santos et al. 2006), o qual foi originalmente ocupado por vegetação de Cerrado e é explorado por culturas anuais há quase 30 anos. O clima da região é do tipo Aw, definido como tropical úmido, com estação chuvosa no verão e seca no in- 
verno, segundo a classificação de Köppen. Apresenta temperatura média anual de, aproximadamente, $25^{\circ} \mathrm{C}$, precipitação total anual de $1.330 \mathrm{~mm}$ e umidade relativa média de $66 \%$ (Centurion 1982).

Antes da instalação do experimento, foi coletada uma amostra composta de solo na área, originada de 20 amostras homogeneizadas e retiradas da camada de 0-0,20 m, para análise de acordo com a metodologia de Raij et al. (1996). Os resultados obtidos foram: $\mathrm{P}$ (resina) $=12 \mathrm{mg} \mathrm{dm}^{-3}$; matéria orgânica $=$ $15 \mathrm{~g} \mathrm{dm}^{-3} ; \mathrm{pH}\left(\mathrm{CaCl}_{2}\right)=5,1 ; \mathrm{K}=2,6 \mathrm{mmol}_{\mathrm{c}} \mathrm{dm}^{-3}$; $\mathrm{Ca}=26 \mathrm{mmol}_{\mathrm{c}} \mathrm{dm}^{-3} ; \mathrm{Mg}=13 \mathrm{mmol}_{\mathrm{c}} \mathrm{dm}^{-3} ; \mathrm{H}+\mathrm{Al}=$ $16 \mathrm{mmol}_{\mathrm{c}} \mathrm{dm}^{-3} ; \mathrm{S}=11 \mathrm{mg} \mathrm{dm}^{-3}$.

O delineamento experimental utilizado foi o de blocos ao acaso com 4 repetições, em um esquema fatorial $8 \times 4$, com 32 tratamentos constituídos pela combinação de culturas antecessoras (milho; milho - Azospirillum brasilense; Urochloa ruziziensis; Urochloa ruziziensis - Azospirillum brasilense; milho + Urochloa ruziziensis; milho - Azospirillum brasilense + Urochloa ruziziensis; milho + Urochloa ruziziensis - Azospirillum brasilense; milho Azospirillum brasilense + Urochloa ruziziensis Azospirillum brasilense) e doses de nitrogênio em cobertura $\left(0 \mathrm{~kg} \mathrm{ha}^{-1}, 30 \mathrm{~kg} \mathrm{ha}^{-1}, 60 \mathrm{~kg} \mathrm{ha}^{-1} \mathrm{e} 90 \mathrm{~kg} \mathrm{ha}^{-1}\right)$. As parcelas experimentais consistiram de sete linhas com 5,0 $\mathrm{m}$ de comprimento, espaçadas $0,45 \mathrm{~m}$ entre si. A área útil para coleta das amostras para avaliações foi composta pelas cinco linhas centrais de cada parcela, desconsiderando-se $0,50 \mathrm{~m}$ das extremidades de cada linha.

As culturas que antecederam o plantio do feijoeiro foram semeadas em novembro de 2011 e, após a colheita do milho, foi realizada a dessecação da área com glyphosate (1.920 $\mathrm{g} \mathrm{ha}^{-1}$ de i.a.) e passagem do desintegrador mecânico, no dia 29/04/2012.

O feijão foi semeado em 08/05/2012, com irrigação por pivô central. Utilizou-se a cultivar Pérola, com plantas do tipo II/III e grãos tipo carioca, no espaçamento de $0,45 \mathrm{~m}$ nas entrelinhas, e regulagem para garantir uma população de 220.000 plantas ha ${ }^{-1}$. As sementes de feijão foram tratadas com o fungicida carbendazim + thiran $\left(45+105\right.$ g do i.a. $100 \mathrm{~kg}^{-1}$ de sementes), visando ao controle de doenças como a antracnose e podridão radicular. A emergência das plântulas ocorreu uniformemente para todos os tratamentos, no dia 13/05/2012, aos cinco dias após a semeadura.

O controle de plantas daninhas em pós-emergência foi realizado com o herbicida fomesafen
(225 $\mathrm{g} \mathrm{ha}^{-1}$ do i.a.), aos 17 dias após a emergência (DAE). Os demais tratos fitossanitários foram realizados de acordo com os recomendados para a cultura, na região.

Com base na análise de solo e recomendação de Raij et al. (1996), utilizou-se, na semeadura, $250 \mathrm{~kg} \mathrm{ha}^{-1}$ da fórmula 04-30-10, para todos os tratamentos. A adubação nitrogenada em cobertura foi realizada no estádio $V_{4-4}$ (quarta folha trifoliada), aproximadamente aos 25 DAE, distribuída manualmente ao lado da linha da cultura, sobre a palha, utilizando-se, como fonte, a ureia ( $45 \%$ de N). Após a adubação, a área foi irrigada (13 mm), com o objetivo de incorporar ao solo o fertilizante aplicado e, assim, minimizar as perdas de nitrogênio por volatilização. O turno de rega seguiu-se, então, com intervalo de três dias.

A colheita foi realizada manualmente em 13/08/2012, aos 92 DAE. Após a secagem, as plantas foram submetidas à trilha mecânica, os grãos pesados e os dados transformados em $\mathrm{kg} \mathrm{ha}^{-1}(13 \%$ base úmida).

A análise econômica foi realizada de acordo a técnica da orçamentação parcial (Noronha 1987). A orçamentação parcial é utilizada para analisar decisões que envolvem modificações parciais na organização de uma atividade produtiva e comparar os acréscimos de custos com os de benefícios da decisão. A melhor alternativa será aquela que oferecer maiores benefícios líquidos ou margens de ganho maiores (Teixeira Filho et al. 2010). Para a realização da análise econômica, foram determinados, para cada tratamento, as receitas e os custos adicionais da adubação nitrogenada realizada em cobertura, considerando-se o preço da tonelada da ureia, em maio de 2012, de R $\$ 1.876,50$ (IEA 2012). O custo do $\mathrm{kg}$ de nitrogênio proveniente da ureia foi de $\mathrm{R} \$ 4,17$ e o da aplicação do N em cobertura, utilizando-se uma adubadora-sulcadora, de R \$36,00 ha (Agria- $^{-1}$ nual 2013).

Com base na produtividade média de grãos de cada tratamento, calculou-se o acréscimo de produtividade proporcionado pela adubação nitrogenada, em relação à testemunha $(\operatorname{sem} \mathrm{N})$. $\mathrm{O}$ valor de produção marginal foi obtido multiplicando-se a produtividade adicional pelo preço recebido pelos produtores de feijão do Estado de São Paulo. O preço médio utilizado foi de $\mathrm{R} \$ 123,25$ por saca de $60 \mathrm{~kg}$ (IEA 2013), que representa o preço médio recebido pelos produtores na safra de inverno, nos últimos 5 anos. 
Já a margem de ganho foi calculada pela subtração do custo marginal da adubação nitrogenada do valor da produção marginal em cada tratamento.

\section{RESULTADOS E DISCUSSÃO}

Os custos com adubação; produtividade de grãos de feijão e acréscimo na produtividade de grãos, devido à adubação nitrogenada; e custo da aplicação e acréscimo financeiro, devido à adubação nitrogenada, são apresentados na Tabela 1. Observa-se que, no tratamento em sucessão ao milho, houve maior acréscimo de produtividade de grãos $(19,26 \%)$ na dose de $60 \mathrm{~kg} \mathrm{ha}^{-1}$ de $\mathrm{N}$ em cobertura de ureia e com a dose de $90 \mathrm{~kg} \mathrm{ha}^{-1}$ de N (18,61\%). Resultados semelhantes foram encontrados para o tratamento com o milho inoculado, sendo que o feijão apresentou maior acréscimo de produtividade na dose de $90 \mathrm{~kg} \mathrm{ha}^{-1}$ de N (18,74\%).

A produtividade obtida nos tratamentos em sucessão ao milho apresentou bons resultados, mesmo na ausência de $\mathrm{N}$ em cobertura $\left(2.987 \mathrm{~kg} \mathrm{ha}^{-1} \mathrm{sem}\right.$ a inoculação e $3.827 \mathrm{~kg} \mathrm{ha}^{-1}$ com a inoculação de Azospirillum brasilense). Dentre as possíveis explicações atreladas aos resultados, pode-se destacar o enriquecimento da matéria seca do milho, por meio da inoculação de sementes e reciclagem dos nutrientes, ao longo do ciclo do feijão.

Tabela 1. Culturas antecessoras, doses de nitrogênio $(\mathrm{N})$, produtividade, acréscimo na produtividade de grãos de feijão, valor de produção e custo com a adubação nitrogenada (Selvíria, MS, 2012).

\begin{tabular}{|c|c|c|c|c|c|}
\hline \multicolumn{3}{|c|}{$\longrightarrow$ Tratamento $\longrightarrow$} & \multicolumn{2}{|c|}{ Acréscimo } & \multirow{2}{*}{$\begin{array}{c}\text { Custo com adubação } \\
\text { nitrogenada }\end{array}$} \\
\hline Cultura & Doses de $\mathrm{N}$ & Produtividade & Produtividade & Valor de produção & \\
\hline antecessora & $\mathrm{kg} \mathrm{ha}^{-1}$ & $\mathrm{~kg} \mathrm{ha}^{-1}$ & $\mathrm{~kg} \mathrm{ha}^{-1}$ & $\mathrm{R} \$$ & $\mathrm{R} \$$ \\
\hline Milho (M) & Testemunha & 2.987 & - & - & - \\
\hline Milho (M) & 30 & 3.392 & 405,08 & 832,09 & 161,10 \\
\hline Milho (M) & 60 & 3.562 & 575,25 & $1.181,65$ & 286,20 \\
\hline Milho (M) & 90 & 3.543 & 555,92 & $1.141,96$ & 411,30 \\
\hline M-Inoculado (I) & Testemunha & 3.827 & - & - & - \\
\hline M-Inoculado (I) & 30 & 3.901 & 74,07 & 152,14 & 161,10 \\
\hline M-Inoculado (I) & 60 & 3.986 & 158,96 & 326,52 & 286,20 \\
\hline M-Inoculado (I) & 90 & 4.545 & 717,42 & $1.473,71$ & 411,30 \\
\hline Urochloa (U) & Testemunha & 3.436 & - & - & - \\
\hline Urochloa (U) & 30 & 3.629 & 193,77 & 398,04 & 161,10 \\
\hline Urochloa (U) & 60 & 3.752 & 316,30 & 649,73 & 286,20 \\
\hline Urochloa (U) & 90 & 4.220 & 784,37 & $1.611,23$ & 411,30 \\
\hline U-Inoculada (I) & Testemunha & 4.401 & - & - & - \\
\hline U-Inoculada (I) & 30 & 4.427 & 25,67 & 52,73 & 161,10 \\
\hline U-Inoculada (I) & 60 & 4.462 & 61,08 & 125,47 & 250,20 \\
\hline U-Inoculada (I) & 90 & 4.532 & 131,38 & 269,87 & 375,30 \\
\hline$M+U$ & Testemunha & 3.577 & - & - & - \\
\hline$M+U$ & 30 & 3.706 & 129,29 & 265,58 & 161,10 \\
\hline$M+U$ & 60 & 3.988 & 410,78 & 843,81 & 286,20 \\
\hline $\mathrm{M}+\mathrm{U}$ & 90 & 4.259 & 681,88 & $1.400,70$ & 411,30 \\
\hline $\mathrm{M}(\mathrm{I})+\mathrm{U}$ & Testemunha & 3.692 & - & - & - \\
\hline $\mathrm{M}(\mathrm{I})+\mathrm{U}$ & 30 & 3.783 & 91,25 & 187,45 & 161,10 \\
\hline $\mathrm{M}(\mathrm{I})+\mathrm{U}$ & 60 & 3.941 & 249,71 & 512,95 & 286,20 \\
\hline $\mathrm{M}(\mathrm{I})+\mathrm{U}$ & 90 & 4.108 & 416,91 & 856,39 & 411,30 \\
\hline $\mathrm{M}+\mathrm{U}(\mathrm{I})$ & Testemunha & 3.789 & - & - & - \\
\hline $\mathrm{M}+\mathrm{U}(\mathrm{I})$ & 30 & 3.886 & 97,80 & 200,91 & 161,10 \\
\hline $\mathrm{M}+\mathrm{U}(\mathrm{I})$ & 60 & 3.963 & 174,22 & 357,87 & 250,20 \\
\hline $\mathrm{M}+\mathrm{U}(\mathrm{I})$ & 90 & 4.132 & 343,91 & 706,46 & 375,30 \\
\hline $\mathrm{M}(\mathrm{I})+\mathrm{U}(\mathrm{I})$ & Testemunha & 3.866 & - & - & - \\
\hline $\mathrm{M}(\mathrm{I})+\mathrm{U}(\mathrm{I})$ & 30 & 3.987 & 121,11 & 248,78 & 161,10 \\
\hline $\mathrm{M}(\mathrm{I})+\mathrm{U}(\mathrm{I})$ & 60 & 4.013 & 146,26 & 300,44 & 286,20 \\
\hline $\mathrm{M}(\mathrm{I})+\mathrm{U}(\mathrm{I})$ & 90 & 4.192 & 325,80 & 669,25 & 411,30 \\
\hline
\end{tabular}

Fonte: dados da pesquisa. 
Vale ressaltar que as bactérias diazotróficas fixadoras de $\mathrm{N}_{2}$, atualmente, são estudadas com muita frequência, pois, além de incrementos de produtividade, há evidências de uma contribuição na produção de fito-hormônios, aumento do volume radicular e, consequentemente, exploração de forma mais abrangente do substrato.

Reis Júnior et al. (2008) comprovaram aumento da matéria seca e acúmulo de nutrientes por planta inoculada, ao estudarem a inoculação de Azospirillum amazonense, em dois genótipos de milho sob diferentes regimes de nitrogênio. Todavia, Binotti et al. (2009), ao avaliarem fontes e doses de nitrogênio em cobertura no feijoeiro de inverno irrigado, no sistema plantio direto, destacaram que a produtividade média do feijoeiro não foi muito alta, talvez em decorrência de a cultura antecessora ter sido o milho. Da mesma forma, Silveira et al. (2005), analisando o comportamento do feijoeiro cultivado em diferentes rotações de culturas, verificaram que as menores produtividades foram obtidas nas rotações cuja cultura antecedente era o milho.

O incremento de produtividade no feijão cultivado em sucessão a Urochloa ruziziensis apresentou resultados variados, quanto à ausência e presença de inoculação. Acréscimos de produtividade mostraram-se mais expressivos no tratamento em que o feijoeiro recebeu $90 \mathrm{~kg} \mathrm{ha}^{-1}$ de $\mathrm{N}(22,83 \%)$. A utilização de gramíneas como a Urochloa ruziziensis, para a formação de palha, no sistema plantio direto, já é uma prática corriqueira no Cerrado brasileiro, região com altas temperaturas e precipitações, o que favorece a decomposição mais acelerada da cobertura vegetal remanescente do cultivo anterior.

Com isso, a manutenção de palhada de qualidade e características favoráveis ao desenvolvimento de culturas sucessoras é de extrema importância para um melhor manejo da adubação nitrogenada. Segundo Stone et al. (2005), o ambiente antecessor procedente de gramínea (Urochloa) proporcionou condições físicas e químicas melhores ao feijoeiro, fato refletido na maior produtividade do mesmo.

Já para os tratamentos em que a cultura antecessora foi o consórcio de milho com Urochloa, destaca-se maior acréscimo de produtividade na ausência de inoculação de Azospirillum brasilense e com aplicação de $90 \mathrm{~kg} \mathrm{ha}^{-1}$ de N (19,06\%), demonstrando que, nos outros tratamentos (com inoculação de Azopirillum no milho, na Urochloa ou em ambos), a adubação nitrogenada surtiu menor efeito, em relação à testemunha.

Uma pesquisa desenvolvida por Binotti et al. (2009), avaliando fontes, doses e modo de aplicação de $\mathrm{N}$ em feijoeiro, no sistema plantio direto, reportou produtividade média de $2.459 \mathrm{~kg} \mathrm{ha}^{-1}$ (aplicação de $90 \mathrm{~kg} \mathrm{ha}^{-1}$ de N), em sucessão a Urochloa + milho, o que sugere novos trabalhos com manejo da adubação nitrogenada em diferentes sistemas de produção. Contudo, Silveira et al. (2005), estudando a adubação nitrogenada no feijoeiro cultivado sob plantio direto, em sucessão de culturas, observaram menores produtividades do feijoeiro em sucessão à cultura do milho consorciado com Urochloa, em qualquer dose de nitrogênio. Já Soratto et al. (2008), estudando o manejo de $\mathrm{N}$ no feijoeiro cultivado em sucessão à cultura do milho solteiro ou milho consorciado com $U$. brizantha, verificaram que foi possível obter produtividade de grãos de, aproximadamente, $3.000 \mathrm{~kg} \mathrm{ha}^{-1}$, mesmo sem a utilização de adubação nitrogenada, quando o feijoeiro foi cultivado em sucessão ao consórcio milho $+U$. brizantha .

Verificou-se que o tratamento com Urochloa ruziziensis, na ausência de inoculação, na dose $90 \mathrm{~kg} \mathrm{ha}^{-1}$, proporcionou maiores acréscimos de produtividade de grãos de feijão, utilizando-se ureia em cobertura (Tabela 1). Por outro lado, deve-se destacar que todos os tratamentos apresentaram produtividades satisfatórias e, com esses resultados, surgem alternativas de sistemas de produção altamente produtivos.

Em relação à análise econômica, nota-se que o milho apresentou respostas semelhantes às obtidas com a aplicação das doses de $\mathrm{N}$, diferentemente do ocorrido com o milho inoculado. A maior margem de ganho encontrada para esse tratamento ( $\mathrm{R} \$ 1.062,41 \mathrm{ha}^{-1}$ ) ocorreu quando utilizou-se no feijoeiro a dose com $90 \mathrm{~kg} \mathrm{ha}^{-1}$ de $\mathrm{N}$ em cobertura (Figura 1).

Fiorentin et al. (2012) observaram que, na sucessão com milho-grão exclusivo, onde o aumento da produtividade pela aplicação de $\mathrm{N}$ em cobertura foi crescente, a única margem bruta positiva de ganho na venda dos grãos de feijão foi alcançada com o uso da dose de $160 \mathrm{~kg} \mathrm{ha}^{-1}$ de N, o que, segundo os autores, demonstra ser indispensável a utilização de elevadas doses de $\mathrm{N}$ em cobertura, para o feijoeiro cultivado em sucessão ao milho-grão. Contudo, Binotti et al. (2009) verificaram que a aplicação de elevadas doses de N (150 kg ha-1 e $\left.200 \mathrm{~kg} \mathrm{ha}^{-1}\right)$, totalmente em se- 


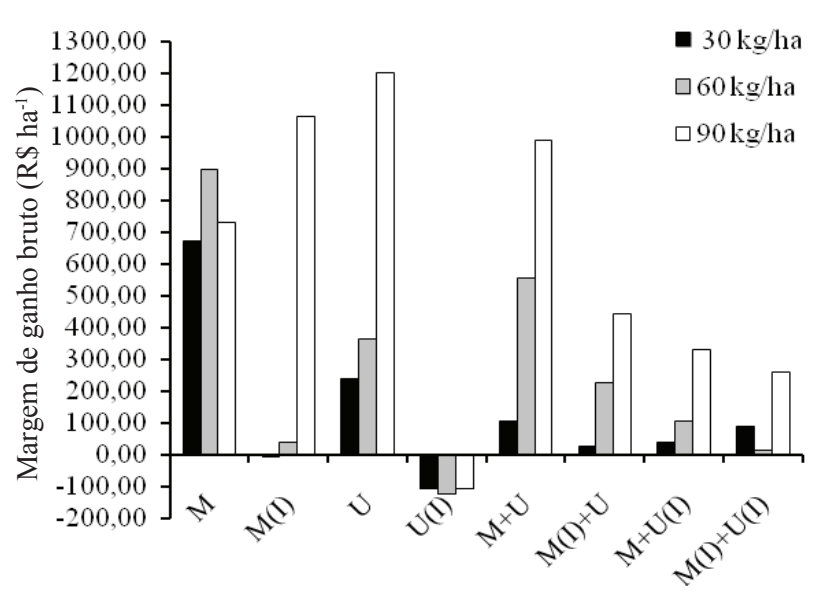

Figura 1. Margens de ganho com a utilização da adubação nitrogenada em feijoeiro de inverno, no sistema plantio direto, após diferentes culturas (Selvíria, MS, 2012). Fonte: dados da pesquisa.

meadura ou $1 / 3$ na semeadura e $2 / 3$ em cobertura no estádio $\mathrm{V}_{4-4}$ do feijoeiro, não proporcionou as maiores margens brutas de ganho, mas sim a aplicação de doses menores (50 kg ha-1).

Para os tratamentos em sucessão a Urochloa, verificou-se que a maior margem de ganho para o feijão foi obtida no tratamento sem a inoculação e na dose $90 \mathrm{~kg} \mathrm{ha}^{-1}$, proporcionando margens brutas de ganho de, aproximadamente, $\mathrm{R} \$ 2.000,00 \mathrm{ha}^{-1}$. Nesta pesquisa, a Urochloa inoculada apresentou-se pouco responsiva à adubação nitrogenada em cobertura, e a margem de ganho bruta, em todas as doses avaliadas (30 kg ha-1, $60 \mathrm{~kg} \mathrm{ha}^{-1}$ e $\left.90 \mathrm{~kg} \mathrm{ha}^{-1}\right)$, foi negativa, demonstrando que o acréscimo na produtividade proporcionado pela adubação nitrogenada não apresentou viabilidade econômica, resultado semelhante ao encontrado por Fiorentin et al. (2012), avaliando adubação nitrogenada de cobertura no feijoeiro de inverno-primavera, em três sistemas de cultivo. Os autores sugerem que, como a palhada de U. ruziziensis pode ter fornecido quantidades significativas de nutrientes, principalmente de $\mathrm{N}$, não houve margem bruta de ganho na venda dos grãos de feijão, para a maioria das doses de $\mathrm{N}$ avaliadas em cobertura.

$\mathrm{Na}$ sucessão do consórcio de milho com Urochloa ruzizinensis, pôde-se observar maior margem de ganho bruto no tratamento sem a inoculação de Azospirillum e na dose de $90 \mathrm{~kg} \mathrm{ha}^{-1}$ (R\$ 989,40 ha-1). Por outro lado, Fiorentin et al. (2012) observaram margem bruta de ganho na venda de feijão em sucessão ao consórcio apenas com a dose de $40 \mathrm{~kg} \mathrm{ha}^{-1}$ de $\mathrm{N}$ em cobertura, sendo positiva, em relação ao tratamento sem aplicação de $\mathrm{N}$.

Segundo Pelegrin et al. (2009), a variabilidade nas respostas do feijoeiro às doses de $\mathrm{N}$, nos diferentes experimentos, tem sido verificada especialmente em função dos níveis de fertilidade do solo e outras técnicas empregadas nos sistemas produtivos, destacando-se o uso de cultivos conservacionistas e sistemas de irrigação.

Diante dos resultados obtidos, a ausência de resposta à adubação nitrogenada, em alguns tratamentos, pode estar relacionada ao cultivo contínuo, que, de acordo com Kluthcouski et al. (2005), principalmente no plantio direto, apresenta uma tendência, ao longo do tempo, de acumular nutrientes no perfil explorado pelas raízes, tornando menos frequente a resposta à adubação com macro e micronutrientes.

Da mesma forma, Gomes Júnior (2006) cita que o feijoeiro em plantio direto responde muito pouco a altas doses de $\mathrm{N}$ em cobertura, quando há grande aporte de fitomassa sobre a superfície do solo, pois, ao avaliar o nitrogênio no feijoeiro em sistema plantio direto sobre diferentes palhadas, esse mesmo autor não verificou efeito dos níveis de $\mathrm{N}$ em cobertura sobre a produtividade do feijoeiro em plantio direto sobre palhada de milheto e Urochloa.

\section{CONCLUSÕES}

1. O maior acréscimo de produtividade de grãos do feijoeiro de inverno irrigado por aspersão foi obtido com a utilização de $90 \mathrm{~kg} \mathrm{ha}^{-1}$ de nitrogênio em cobertura, em sucessão a Urochloa ruziziensis, sem a inoculação de Azospirillum brasilense.

2. O feijoeiro cultivado em sucessão a Urochloa ruziziensis inoculada com Azospirillum brasilense não respondeu economicamente à adubação nitrogenada em cobertura.

3. Recomenda-se, para a obtenção da maior margem de ganho, a aplicação de $90 \mathrm{~kg} \mathrm{ha}^{-1}$ de nitrogênio em cobertura, na cultura do feijão em sucessão às culturas estudadas, com exceção de Urochloa ruziziensis inoculada.

\section{REFERÊNCIAS}

AGRIANUAL: Anuário da agricultura brasileira. São Paulo: Agrianual, 2013.

ALCÂNTARA, F. A. et al. Adubação verde na recuperação da fertilidade de um Latossolo Vermelho-Escuro 
degradado. Pesquisa Agropecuária Brasileira, Brasília, DF, v. 35, n. 2, p. 277-288, 2000.

AMADO, T. J. C.; MIELNICZUK, J.; AITA C. Recomendação de adubação nitrogenada para o milho no RS e SC adaptada ao uso de culturas de cobertura do solo, sob sistema de plantio direto. Revista Brasileira de Ciência do Solo, Viçosa, v. 26, n. 2, p. 241-248, 2002.

BARBOSA FILHO, M. P.; FAGERIA, N. K.; SILVA, O. F. Fontes e métodos de aplicação de nitrogênio em feijoeiro irrigado submetido a três níveis de acidez do solo. Ciência e Agrotecnologia, Lavras, v. 28, n. 4, p. 785-792, 2004.

BARBOSA FILHO, M. P.; FAGERIA, N. K.; SILVA, O. F. Fontes, doses e parcelamento da adubação nitrogenada em cobertura para feijoeiro comum irrigado. Ciência e Agrotecnologia, Lavras, v. 29, n. 1, p. 69-76, 2005.

BARBOSA FILHO, M. P.; SILVA, O. M. Adubação e calagem para o feijoeiro em solo de Cerrado. Pesquisa Agropecuária Brasileira, Brasília, DF, v. 35, n. 7, p. 1317 1324, 2000.

BINOTTI, F. F. S. et al. Fontes, doses e modo de aplicação de $\mathrm{N}$ em feijoeiro no sistema plantio direto. Bragantia, Campinas, v. 68, n. 2, p. 473-481, 2009.

BOER, C. A. et al. Ciclagem de nutrientes por plantas de cobertura na entressafra em um solo de Cerrado. Pesquisa Agropecuária Brasileira, Brasília, DF, v. 42, n. 9, p. 12691276, 2007.

BRASIL. Ministério da Agricultura, Pecuária e Abastecimento. Informações sobre a cultura do feijão. 2013. Disponível em: <http//www.agricultura.gov.br>. Acesso em: 17 jul. 2013.

CENTURION, J. F. Balanço hídrico da região de Ilha Solteira. Cientifica, Jaboticabal, v. 10, n. 1, p. 57-61, 1982.

CREPALDI, S. A. Contabilidade rural: uma abordagem decisorial. 2. ed. São Paulo: Atlas, 1998.

COMPANHIA NACIONAL DE ABASTECIMENTO (Conab). Acompanhamento da safra brasileira de grãos 2014/2015: segundo levantamento, outubro 2014. 2014. Disponível em: $<$ http://www.conab.gov.br $>$. Acesso em: 25 nov. 2014.

FIORENTIN, C. F. et al. Adubação nitrogenada de cobertura no feijoeiro de inverno-primavera em três sistemas de cultivo. Semina: Ciências Agrárias, Londrina, v. 33 , n. 6 , p. 2825-2836, 2012.

GASSEN, D. N.; GASSEN, F. R. Plantio direto. Passo Fundo: Aldeia Sul, 1996.

GOMES JÚNIOR, F. G. Nitrogênio no feijoeiro em sistema de plantio direto sobre diferentes palhadas: produtividade, composição química e qualidade fisiológica de sementes. 2006. 106 f. Dissertação (Mestrado em Agronomia/ Sistemas de Produção) - Faculdade de Engenharia, Universidade Estadual Paulista, Ilha Solteira, 2006.

HUNGRIA, M. Inoculação com Azospirillum brasilense: inovação em rendimento a baixo custo. 2011. Disponível em: <http://www.cnpso.embrapa.br/download/doc325. pdf $>$. Acesso em: 31 out. 2012.

INSTITUTO DE ECONOMIAAGRÍCOLA(IEA). Preços médios mensais pagos pela agricultura. 2012. Disponível em: <http://www.iea.sp.gov.br/out/index.php>. Acesso em: 28 jul. 2013.

INSTITUTO DE ECONOMIA AGRÍCOLA (IEA). Previsões e estimativas das safras agrícolas do Estado de São Paulo, ano agrícola 2012/13. 2013. Disponível em: $<$ http://www.iea.sp.gov.br/out/ index.php>. Acesso em: 28 jul. 2013.

KLUTHCOUSKI, J. et al. Manejo antecipado do nitrogênio nas principais culturas anuais. Santo Antônio de Goiás: Embrapa Arroz e Feijão, 2005. (Documentos, 188).

MALAVOLTA, E. Adubos nitrogenados. In: MALAVOLTA, E. Abc da adubação. 4. ed. São Paulo: Agronômica Ceres, 1979. p. 25-39.

NORONHA, J. F. Projetos agropecuários: administração financeira e avaliação econômica. 2. ed. São Paulo: Atlas, 1987.

PELEGRIN, R. et al. Resposta da cultura do feijoeiro à adubação nitrogenada e à inoculação com rizóbio. Revista Brasileira de Ciência do solo, Viçosa, v. 33, n. 1, p. 219226, 2009.

RAIJ, B. V. et al. Recomendações de adubação e calagem para o Estado de São Paulo. 2. ed. Campinas: Instituto Agronômico, 1996. (Boletim técnico, 100).

RAPASSI, R. M. A. et al. Níveis e fontes de nitrogênio sobre o feijoeiro de inverno. Cultura Agronômica, Ilha Solteira, v. 12, n. 1, p. 103-115, 2003.

REIS JÚNIOR, F. B. et al. Inoculação de Azospirillum amazonense em dois genótipos de milho sob diferentes regimes de nitrogênio. Revista Brasileira de Ciência do Solo, Brasília, DF, v. 32, n. 3, p. 1139-1146, 2008.

SANTOS, H. G. et al. (Eds.). Sistema brasileiro de classificação de solos. 2. ed. Rio de Janeiro: Embrapa Solos, 2006.

SILVA, I. F.; MIELNICZUK, J. Avaliação do estado de agregação do solo afetado pelo uso agrícola. Revista Brasileira de Ciências do Solo, Viçosa, v. 21, n. 2, p. 313319, 1997. 
SILVEIRA, P. M. et. al. Adubação nitrogenada no feijoeiro cultivado sob plantio direto em sucessão de culturas. Pesquisa Agropecuária Brasileira, Brasília, DF, v. 40, n. 4, p. 377-381, 2005.

SORATTO, R. P. et al. Épocas de antecipação do nitrogênio para feijoeiro no sistema plantio direto após milho solteiro ou consorciado com Brachiaria brizantha. In: FERTBIO 2008, Londrina, 2008. Resumos... Londrina: Sociedade Brasileira de Ciência do Solo, 2008. 1 CD-ROM.
STONE, L. F. et al. Efeito do ambiente antecessor em alguns atributos do solo e na produtividade do feijoeiro. In: CONGRESSO NACIONAL DE PESQUISA DE FEIJÃO, 8., 2005, Goiânia. Anais... Santo Antônio de Goiás: Embrapa Arroz e Feijão, 2005. p. 800-803.

TEIXEIRA FILHO, M. C. M. et al. Análise econômica da adubação nitrogenada em trigo irrigado sob plantio direto no Cerrado. Revista Ceres, Viçosa, v. 57, n. 4, p. 446-453, 2010. 